\title{
The impacts of formative system on the landslides of Iran
}

\author{
Mojgan Entezari Najafabadi, Somayeh Shahzeidi and Masoumeh Rashidi
}

Department of Geography, University of Isfahan, Isfahan, Iran

A R T I C L E I N F O A B T R A T

Article history:

Received October 1, 2011

Received in Revised form

November, 14, 2011

Accepted 15 December 2011

Available online

22 December 2011

Keywords:

Landslide

Cold hole

Hot hole

Astronomic climate

\begin{abstract}
Landslide is one of the most challenging disasters on the earth, which is believed to cause other natural catastrophic incidents. Normally, in studying landslide we investigate different influencing factors such as gender land, atmospheric rainfall, gradients' change, earthquake, volcanic eruption, subterranean water vibration, and human causes in the form of different models. These facts are blamed as the main share in appearing this phenomenon. However, correlative and sufficient condition for genesis such a phenomenon is historical base of lands' bed, which needs specific formative process. There are several studies focused on distribution and dispersion of slides and their reasons. In this paper, we investigate the behavior of landslide and its effects on instigating instabilities. The preliminary results indicate that distribution of this phenomenon is associated with climate from a side and historical formative process on the other side.

The weather condition of Iran is divided into four groups of cold, hot, humid and humid hot hole. Every region has its own special geomorphic properties and either directly or indirectly affects on landslide occurrence. In order to study this effect, we use Arc GIS 9.3 software dispersal map of Iran's main landslides and formative systems on the other side and by local analyzing these two collections are evaluated based on their vicinity relationship using localstatistical techniques. Results of this research shows that the main part of this landslide occurs in cold hole and humid hole and only about 8 percent are happens in hot holl. In addition, density of landslides are more in thermodynamic bound of cold and hot hole as well as cold and humid hole.
\end{abstract}

\section{Introduction}

Geomorphologic studies show that there is an organic relationship between climate and landforms of earth. This relationship is so strong that the Geomorphology scientists believe that geomorphologic phenomena are acquired through internal and external formation power (Zomorodian, 2002). The appearance of most of external geomorphologic phenomena depends on various climatic zonal. Climate has significant role in the creation of geomorphic forms and their changes during time. However, we cannot claim that all types of climates affect on geomorphic changes.

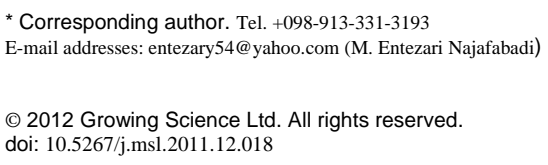


In other words, weight and combination of determined parameters in each climate must reach the level in which climate enables to landform (Abbasi, 2008). Landslide is one of the geomorphologic phenomena and it is affected by formative systems. Landslide is a mass movement of the founding materials of earth from a slope from higher level to the lower level in the slope (Ramesht, \& Shoshtari, 2005).

Many researchers tried to present models for zoning of landslide hazard. In other words, they wanted to reach the map of landslides` zoning based on inductive method. They investigated different effective factors in the slides occurrence and their effects on the distribution of slides. However, in this paper, the authors use deductive method in order to reach the details from the whole and also implement the formative systems, cold, hot and humid holes associated with temperature, moisture and limits to predict and determine the zoning of landslide hazard. The terms, hot, cold and humid holes derived from hot and cold pool of air in climatology, cold pool is a place, which is surround by hot air and hot pool contains a high temperature (American Meteorological Society, 2009). In geomorphology, these regions are different from hot and cold holes in climatology, hot and cold holes against hot and cold pools are fixed spatially, and also they depend on the geomorphologic structure of the region.

\section{Background of study}

There are many different studies about the effects of climatic changes on slide occurrence (Tamura et al., 2002; Khan et al., 2005; Martin et al., 2010). Claude et al. (1999) studied the slides of south of France, indicated that there is a good interrelationship between climatic change and landslide, although the amount of this interrelationship depends on type and time of slide occurrence. Also, Martin et al. (1999) investigated the slides` sediments in East of Chloride, stated that most of mass movements occurred in two periods during Quaternary. The oldest groups of slides occurred in moisture era and in equatorial and semi-equatorial regions in south of America.

\section{Methodology}

We first investigate the air photographs and field studies to find the place of 4289 landslides in Iran on DEM of country using Software Arc GIS 9.3 (digital altitudinal model with $85 \mathrm{~m}$ cellular size gained from the digital photos of radar). In order to determine the position of hot-cold and humid centers in Iran, the statistics of 452 climatic and synoptic stations of Iran investigated and analyzed. Among these stations, the stations with temperatures 5 degree or under 5 degree during 3 or 4 months are called cold stations and the stations with temperatures over 5 degree during 3 or 4 months are called hot stations. In addition, the stations with moisture over average are called humid stations. The average of 3 cold months in cold stations are calculated for the statistical period and then the map of formative systems are prepared by IDW method and by using Software Arc GIS9. Finally, after overlapping this map with distributive map of slides, we calculate the extent of hot, cold and humid zones and number of occurred slides, the percentage of occurred slides in each region is determined and analyzed. After Integrating of these two maps, the conditions are prepared to analyze the place of slide occurrence and its relationship to hot, cold and humid cells. Then, creating proportion between number of slides and the extent of climatic zones and calculating an index, the effects of these zones on the slides occurrence are investigated. 


\section{Hot-Cold and humid holes in Iran}

In order to create a spatial numerical models for hot-cold center, the average temperature of meteorological datum of 452 climatologic and synoptic stations in Iran are extracted and we consider a hot and a cold season for each station based on periodic range of recording the datum in the station. 217 stations out of these stations are called cold station where their temperatures were lower than or equal to $5^{\circ} \mathrm{C}$ during 3 to 4 months and 120 stations in the north and west of Iran had moisture over average moisture and humid stations. After that the map of formative systems are prepared by IDW method.

\section{IDW (Inversal Distance Weight)}

There are two categories of interpolation techniques; deterministic and geo-statistic. Deterministic interpolation techniques create surface based on measured point or mathematical formulas. Method such as Inversal Distance Weight(IDW) are based on the extant of similarity of cells while method such as Trend fits a smooth surface defined by mathematical function. The IDW function is used when the set of point is dense enough of capture the extent of local surface variation needed for analysis. IDW determines cell values using a linear - weighted combination set of sample point. The weight assigned is a function of the distance of an input point from the output cell location. The greater the distance, the less influence the cell has on the output value (Childs, 2004).

\section{Relationship between slides and formative systems}

As mentioned before, based on climatic formative systems, Iran is classified into four regions. Regarding temperature, moisture and rainfall, each of these systems has special characteristic. These characteristics present independent formative framework, somehow it can explain the differences of morphology in the area of these systems. Moreover, these formative systems have special dynamic relationship with each other, which can be clarified in the cyclic and seasonal scale. If numbers of slides are divided by the extent of formative systems in each periodic era, the index I can be calculated.

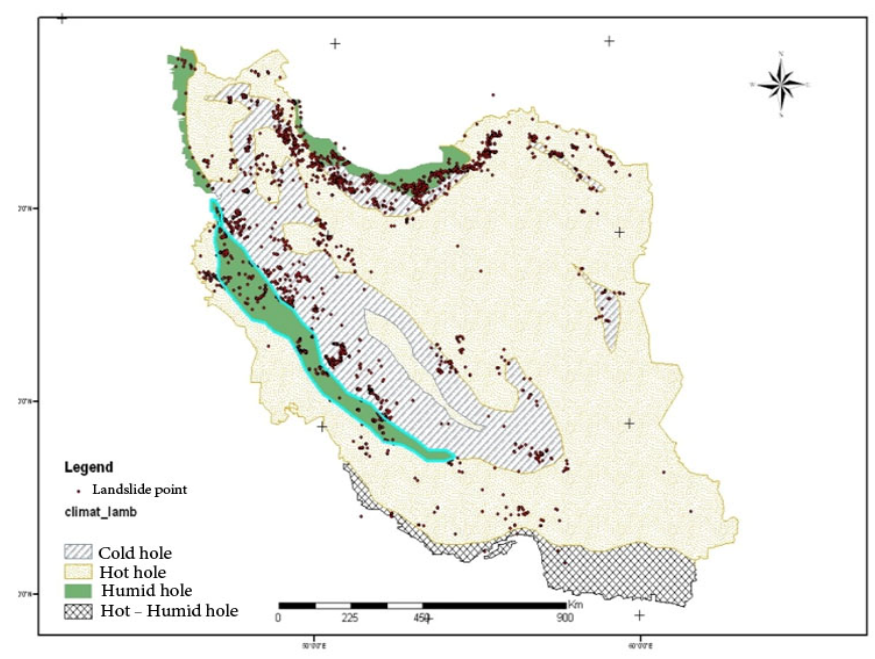

Fig. 1. Distribution of slides in hot, humid and cold holes 
The investigation of this index and calculation of slides' percentage in each formative systems show that, there was a significant difference between the size of hot and cold holes. In other words, hot holes are very vast but the main part of this landslide has occurred in cold holl (33 percent) and humid holl (58 percent) and only about 8 percent are in hot holl. Rainfall and high moisture in humid holes increase the likelihood of landslide and this is very logical.

\section{Table1}

Percentage of slides occurrence in each formative system

\begin{tabular}{lcccc}
\hline Title & Area (Hectares)(AZ) & No. Landslides (NI) & Index NI/AZ*1000 & Index \% \\
\hline Hot -humid holes & 87827 & 6 & 0.06 & 0.37 \\
Hot holes & 1084340 & 1421 & 1.3 & 8.1 \\
Cold holes & 339202 & 1781 & 5.2 & 32.5 \\
\hline Humid holes & 114796 & 1087 & 9.4 & 58 \\
\hline
\end{tabular}

Generally, mass and mountainside movements are classified in different groups based on their founding materials, type of movements, speed and the size of activity. According to these classifications, the movements include two groups; vertical and lateral groups and each group is divided into minor groups, respectively (Varnes, 1978). The main groups of these movements involve slide, mountainside fall, creep, cell flexion and mud flow (Carson \& Kirkby, 1972).

One of the most primary fields for falling and sliding is the mechanical destruction of rocks, which could occur in cold centers. Mechanical destruction is associated with the changes of temperature. Because of changes of temperature, the rocks are extended and contracted and then they cracked, called Thermoclasty. It is not so important, when temperature rises higher than $0^{\circ} \mathrm{c}$, but the freezing phenomenon is the key factor in falling rocks. In 1965, Rapp demonstrated when temperature rises up from the degrees under zero to the upper degrees; it could be an important factor in falling rocks. On the other hand, almost all of rocks, which are appeared on the earth partly have various small and big hole, crack and seam. When the weather is rainy, some water penetrates into the rocks easily. If the rain is heavy and steady, most of the holes are saturated by water. When water is freezing inside the rocks, its volume increases up to $10 \%$ and the rock breaks into pieces. The rocks disintegrate and shatter depending on many factors such as porosity, size of cracks in the rock and other physical characteristics like texture and structure of rock. It can create different mass movements.

After arriving interglacial era (summer of earth) and increasing temperature, the expansion of hot centers districts the cold ones. Settling hot cell on top of Iran, temperature increases in all parts of the country especially in Isfahan, cold centers decrease and they exist only in the latitudes and finally hot centers become fixed. Quick cold or humid changes develop special morphic forms based on dominated formative system in the area. For instance, quick changes of temperature in continents especially in the slopes of mountains was the main reason for melting the ice resources, to flow a huge energy of water and to prepare an appropriate condition for slides occurrence in these areas in a few time.

Therefore, it is considerable, that the effects of momentary and quick changes on formative systems are different from the effects of permanent, constant and slow changes. In slow changes, environment always can be adapted by the new conditions. When these kinds of changes occure, formative systems often are changed completely and produced special geomorphologic phenomenon on the 
external surface of earth. In other words, each of them is an evidence for the dominated formative system or is a climatic system. The existence of each of mentioned era in Iran develops a special formative system and their effects can be traced and recognized as geomorphologic evidences and outlooks. Because of developing hot centers and increasing temperature, in the event of cold centers in which the glacial systems were activated, another system was substituted with the glacial system. Increasing temperature, caused snow boarders' rise to the higher areas and glacial lateral systems were activated instead of them.

Main mechanism in glacial lateral systems includes constant freezing and melting. Freezing is so weak in dry environments but so strong in humid environments. In humid environments, water penetrates into the rocks and sediments as well. When the temperature is below zero, they are freezing and their volumes increase and finally the rocks crack and the soil is puffing. While ice melts, the pieces of rocks connected to each other by ice were separated and fell. Totally, most of slides and falls occurred during melting (Rapp, 1960). Water produced by melting and deep sediments of freezing saturated the soil and produced a special kind of solifloxin called gelifloxin (material movement like a cloyed in glacial environments). This movement occurred when the soil was saturated by water completely, because soil freezing prevents from penetrating water to the lower levels.

\section{Conclusions}

According to the investigation on the effective factors in slide occurrence, it is evidence that recognizing the area prone to slide, is one of the most important methods to prevent and decrease losses caused by this phenomenon. One of the main points about the distribution of landslides in Iran is that these forms follow and affect stellar climatic areas as a symbol of formative identical characteristic. The results show that, there are 4 climatic formative systems in Iran.

Calculating the index of slide shows that percentage of this index in cold hole and humid holes are high. About $58 \%$ of slides regardless of their extents were located in the humid holes and $33 \%$ in cold holes. Main effective factors in this kind of slide occurrence involve sudden changes in temperature, extension and contraction of rocks, freezing water in cracks and seams of rocks. In addition, thermodynamic relationships between hot and cold centers increase the likelihood of landslide. In cold season, cold holes affected by glacial system, sediments were freezing deeply and rocks cracking because of changes in temperature and freezing water in cracks and seams.

During hot season, hot interrelationships between hot and cold holes caused contraction in cold holes and extension in hot holes, somehow a large extent of areas located in the limits of cold holes, developed to the limits of hot holes. These sever changes in temperature resulted in the changes of glacial systems in to glacial lateral systems and finally melted sediments saturated soil by water and developed a huge amount of mass movements of slides like as solifloxin and gelifloxin. Only 9\% slides are evidence in hot holes. These slides usually occurred for many reasons such as; tectonic factors like earthquake and physiological factors. In sum, density of slides in these areas is low because of reasons like changes of temperature, slope and lithology. 


\section{Acknowledgment}

The authors would like to deeply appreciate for the comments of anonymous referees for constructive comments on earlier version of this work.

\section{References}

American meteorological society (2009).

Abbasi, A . (2008). Spatial and genetic analysis of cone shaped of Iran. A dissertation for the degree of PhD in Islamic Azad University of Najaf Abad.

Carson, M. A., \& Kirkby, M. J. (1972). Hill slope Form and Process. Cambridge University Press.

Chorley, R. J., Schumm, S. A. \& Sugden, D. E. (1996). Geomorphology. London, $3^{\text {rd }}$ ed., Samt Pub.

Childs, C. (2004). Interpolation surface in Arc GIS spatial Analyst. ESRI Education services.

Flageollet, J. C., Maquaire, O., Martin, B., \& Weber, D. (1999). Landslides and climatic conditions in the Barcelonnette and Vars basins (Southern French Alps, France) Geomorphology, 30(1-2), 6578.

Khan, Md. S. H., Parkash, B., \& Kumar, S. (2005).Soil-landform development of a part of the fold belt along the eastern coast of Bangladesh. Geomorphology, 71(3-4), 310-327.

IAEG commission on landslide (1990). Suggessted Nomenclature for landslides. Bulletin of the International Association of Engineering Geology, 41, 13-15.

Martin, D., Lal, T., Sachdev, C.B., \& Sharma, J.P. (2010). Soil organic carbon storage changes with climate change, landform and land use conditions in Garhwal hills of the Indian Himalayan mountains. Agriculture, Ecosystems \& Environment, 13B(1-2), 64-73.

The map of landslides diffusion, research center of soil and watershed conservation, (2006).

Varnes, D. J. (1978). Slop Movement Type and Processes. In Special Report 176: Landslide: Analysis and Control (R.L.Schster \& R.J.Krizek, eds.), TRB. National Research Council , 1978, Washington, D.C., 11-33.

Ramesht, M., \& Shoshtari, N. (2005). Icing zone works and glacial effects in Salafchegan in Qom. Geographical Studies, 119-132.

Rapp, A. (1960). Recent development of mountain slopes in Karkevagge and surroundings, northern Scandinavia. Geografiska Annaler, 42, 71-200.

Tamura, T., Li, Y., Chatterjee, D., Yoshiki, T., \& Matsubayashi, T. (2002). Differential occurrence of rapid and slow mass movements on segmented hillslopes and its implication in late Quaternary paleohydrology in Northeastern Japan. CATENA, 48(1-2), 89-105.

Zomorodian, G. (2002). Geomorphology of Iran. Climatic and external dynamic processes, Ferdosi University of Mashad. 